\title{
THE DEVELOPMENT OF PINNATE LEAVES
}

\author{
FREDERIC T. LEWIS
}

BeTweEn 1837 and 1861 the development of leaves occasioned a lively controversy among botanists. Schleiden's school maintained that a leaf grows at its base,- - not at its tip, and that this is the fundamental distinction between leaf and branch. Basal growth was demonstrated by painting the outer half of a young leaf and observing the diminishing proportion of the painted area as the leaf grew; it was also observed that many actively growing leaves of monocotyledons were dead and withered at their distal ends. The leaflets of compound leaves were thought to arise at the base and to be pushed outward so that the stipules and basal leaflets of the mature leaf were the last of all parts to appear. Contrary to all this Nägeli declared that the stipules are formed first, and that lateral leaflets are cut off from the terminal leaflet so that the apical lateral leaflets are the youngest. Since the basal part of the leaf forms first and grows longest it becomes the broadest part, but the growing tip remains slender. In 1861 Eichler introduced his thorough study of leaf development with the statement, "The nature and development of leaves have been a subject of controversy among botanists until recent times, and the issue is still undecided." Since then, however, the attention of investigators has been directed chiefly to newer problems, and the subject remains about as Eichler left it. Ten years ago, quite unaware of this controversy, the writer gathered and sketched a selection of mature rose, blackberry, and sumac leaves which presented the problem in very clear terms. In the present paper some of these leaves are to be described, after which the embryological interpretation of their peculiarities will be considered, and finally their evolutionary significance will be noted.

Mature Leaves.- The group of rose leaves (Fig. 1) was gathered from different bushes and from various parts of the stem. Although they all probably came from Rosa lucida Ehrh., other species of wild rose may be included. The arrangement of the leaves is 
purely arbitrary, but it indicates a possible mode of development. The lower pair of leaflets in $b$ is close to the stipules; in $c$ and $d$ the length of petiole separating them from the stipules is successively greater. In $e$ one stipule is enlarged and leaf-like at its tip, having a coarsely serrate upper margin and containing a mid-rib; in $f$ there is a complete leaflet close to the stipule. $G, h$ and $i$ show an imperfectly developed pair of leaflets in relation with the stipules. $J$ and $k$ have a perfect pair close to the stipules, and in $l$ and $m$ this third pair is more distally placed since the petiole is longer. Thus the series suggests that the third pair of leaflets is developed from the outer portion of the stipules. Forms showing the similar addition of a fourth pair of leaflets may easily be obtained, together with those which present the first and second pairs in relation with the stipules. In the leaf $a$ there is an unpaired fourth leaflet on the right, but the stipule on the left is distinctly longer than its mate.

From the examination of mature rose leaves it appears, therefore, that leaflets are added from the stipules. It would be inferred that the basal leaflets are the last to develop, but that the stipules arise before the first pair of lateral leaflets. In the rose neither the terminal nor the basal leaflets show lobation or other evidence of leaflet production.

In the "high-bush" blackberry, Rubus sp.?, there is a different process of leaflet formation as shown in Figure 2. $A$ is a simple leaf with stipules. In $b, c$, and $d$, by the lobation of the basal portion of the leaf blade, the first pair of leaflets is produced. The stipules are not involved in their formation. In $e, f, g$ and $h$, a second pair of leaflets appears by the lobation of the basal leaflets. Thus the mature blackberry leaves suggest that leaflets arise, not from the stipules, but from the basal leaflets.

The sumac, Rhus copallina L., presents a third type as seen in Figure 3. The leaf $a$ has five pairs of leaflets together with an undivided terminal leaflet; $b, c$, and $d$ also have five pairs, but the terminal leaflet is lobed or divided and suggests the origin of the sixth pair of leaflets shown in $e$. In the sumac the addition of new leaflets is from the terminal leaflet, and never from the basal as in the blackberry. There are no stipules.

Leaves of the sumac type are generally called basifugal (Goebel 


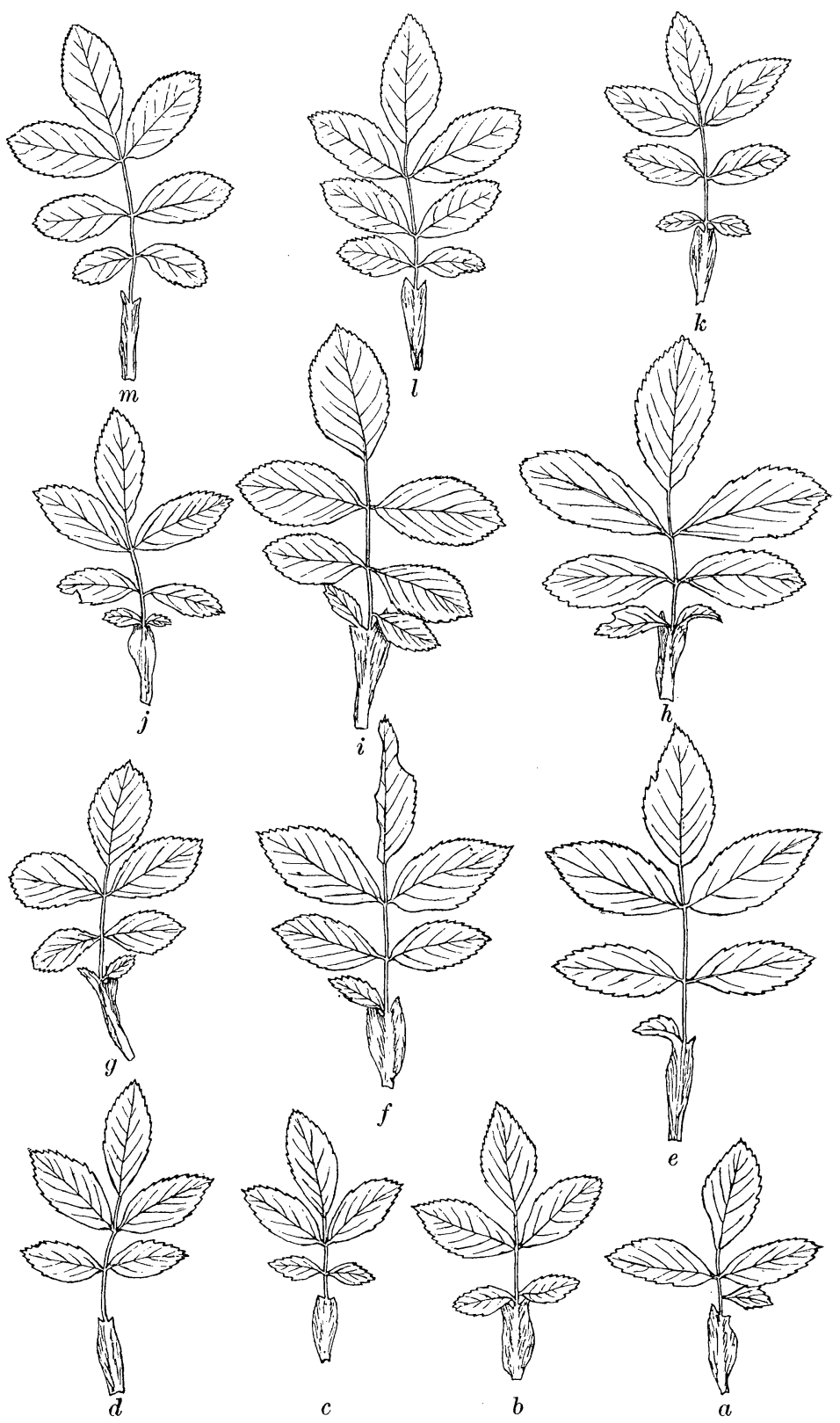

Fig. 1.- Leaves of the wild rose, Rosa lucida, Ehrh. $\frac{1}{2}$ natural size.

This content downloaded from 192.148.225.018 on July 16, 2017 21:20:14 PM All use subject to University of Chicago Press Terms and Conditions (http://www.journals.uchicago.edu/t-an 
prefers akropetal). Nägeli who believed that all leaves grew near their apices, studied particularly the leaf development in Aralia spinosa L. which is of the basifugal type. ${ }^{1}$ At the distal ends of its chief subdivisions there are lobed leaflets like those of the sumac. Steinheil ${ }^{2}$ who believed that leaf-growth was generally basal, considered that compound leaves were an exception in that their outermost leaflets were the youngest. Trécul ${ }^{3}$ recognized both the basifugal type of compound leaf and the basipetal which would include both the blackberry and rose. He distinguished also a mixed and a parallel type. These are discussed and rearranged by Eichler $^{4}$ (pp. 16-21). In addition to basifugal and basipetal he recognizes six types, namely divergent, convergent, simultaneous, ternary, cyclical, and parallel (but the last is not in Trécul's sense). In the divergent form, the leaflets develop from the center toward both ends of the leaf; in convergent leaves they develop from both ends toward the center; and in the simultaneous type all the leaflets arise at one time. When a single leaflet divides to make three, the distinction between basifugal and basipetal can scarcely be made since the next pair of leaflets may arise from the terminal leaflet as in the sumac, or from the basal leaflets as in the blackberry; but these ternary leaves are usually counted as basipetal. Cyclical leaves may be either basipetal or basifugal; the two lateral basal portions of the blade become connected around the petiole in peltate form, as in Ricinus, Lupinus and others. In the parallel type, on both sides of the median line vertical divisions arise, parallel with the periphery of the leaf. This occurs in Foeniculum and others. In the parallel form the divisions may be basipetal or basifugal. Eichler states (p. 18) that "Other developmental types have never been observed either by me or by earlier investigators; but considering the manifold forms of leaf development doubtless other types exist."

${ }^{1}$ Nägeli, C. Wachsthumsgeschichte des Blattes von Aralia spinosa Lin. Pflanzenphysiologische Untersuchungen, Heft 1, Zürich, 1855.

${ }^{2}$ Steinheil, Ad. Observations sur le mode d'accroissement des feuilles. Ann. des Sci. Nat., Partie Bot., 1837, ser. 2, vol. 8, pp. 257-307.

3 Trécul, A. Mémoire sur la formation des feuilles. Ann. des Sci. Nat., Partie Bot., 1853, ser. 3, vol. 20, pp. 235-314.

${ }^{4}$ Eichler, A. W. Zur Entrickelungsgeschichte des Blattes. Marburg, 1861, $60 \mathrm{pp}$. 
In Eichler's tables Rhus typhina is with the basifugal leaves; "Rosa canina, tomentosa, arvensis, etc." are with the basipetal.
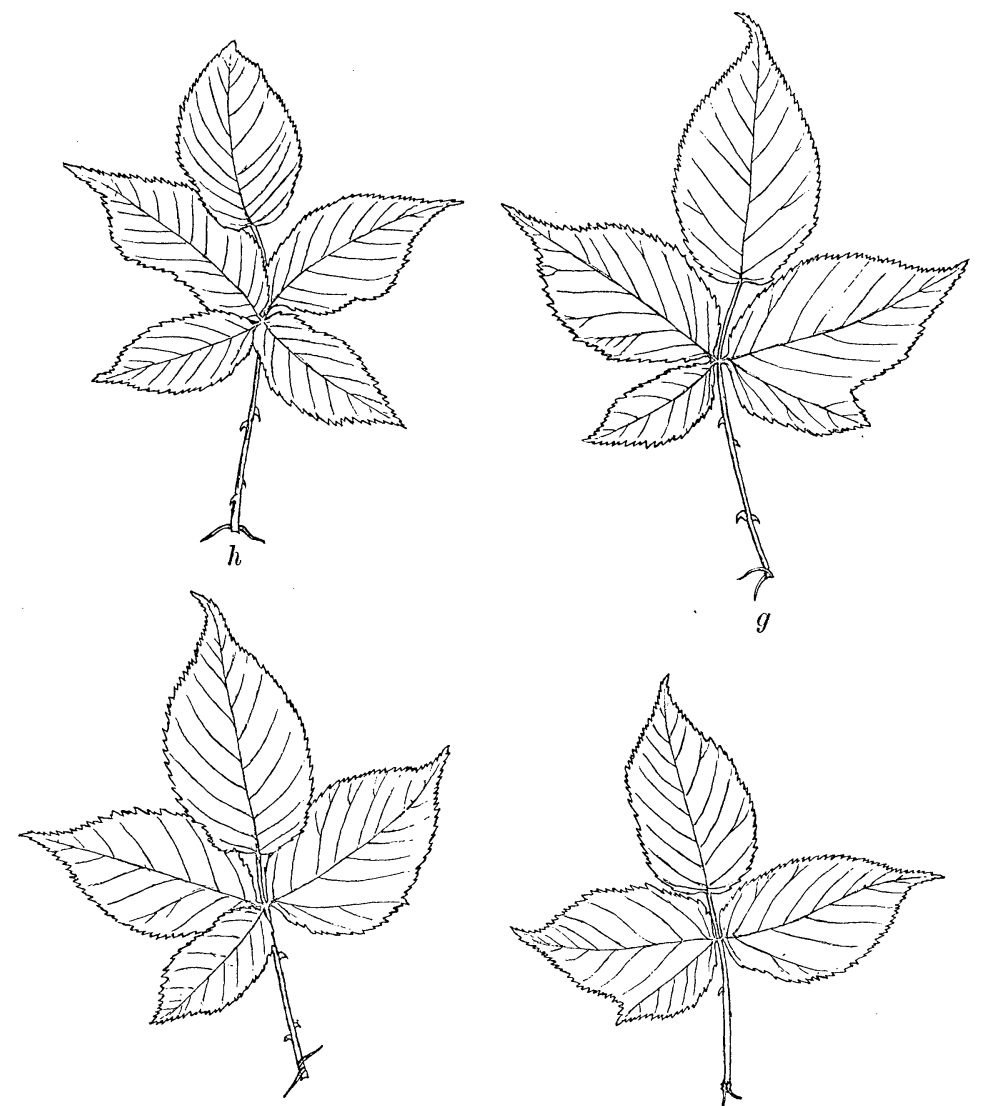

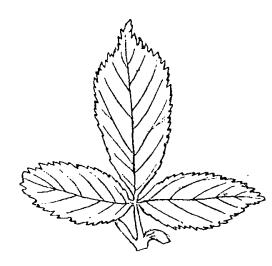

$d$ $f$

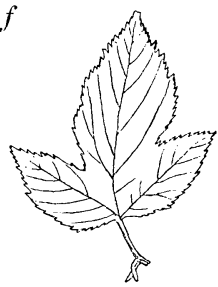

$c$

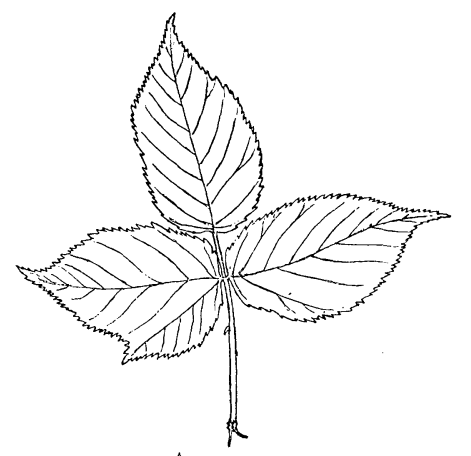

FIG. 2.- Leaves of the high bush blackberry, Rubus sp.? $\frac{1}{2}$ natural size.

Rubus is not included, but the similar Potentilla is classed with the rose. Goebel ${ }^{1}$ likewise places "all digitate leaves" with the

${ }^{1}$ Goebel, K. Organographie der Pflanzen. Part 2, Heft 2, Jena, 1900. 
rose and calls them basipetal (p. 525). There are two serious objections to grouping the rose leaf with that of the blackberry or potentilla. Neither the terminal nor the basal leaflets of the rose are ever lobed to produce new leaflets as in the blackberry; and in the blackberry the stipules are not involved in leaflet production as in the rose. If the term basipetal is to be retained for the blackberry and potentilla type, the leaf formation in the rose may be described as stipular.

Embryonic Leaves.- The interpretation of series of leaves such as those shown in Figures 1-3 depends upon the study of their embryonic development, for they are mature leaves and can never add to their lobes or leaflets. The number of these parts is determined. before the leaf expands.

According to Eichler (loc. cit.) a leaf may begin in two ways. In some cases, immediately below the tip of the axis, there arises: simultaneously in all its parts, a wall-like proliferation of cambial tissue corresponding to the entire insertion of the future leaf together with its stipules, if it is to have any. In other cases, beneath the growing tip of the axis a low papilla or conical proliferation appears, which quickly spreads laterally so that more and more of the circumference of the stem is involved in the leaf formation. This spreading ends before the leaf begins to be subdivided into lobes. In one of these two ways the primordial leaf is formed, from which (and never from the stem) all parts of the mature leaf develop. They are not pushed out from the stem. The primordial leaf forms from the stem; after that, all growth of the leaf is only an elaboration of the primordial leaf.

After its formation, the primordial leaf begins to differentiate a stationary basal zone, which is concerned only with the formation of stipules, and a vegetative outer zone which produces the petiole and blade. Petiole formation always follows blade formation; the expansion is at least indicated before the stalk begins. In palmate and pinnate leaves all of the main subdivisions are generally mapped out before the appearance of the petiole. The mid-rib may be present before the blade expands, as is true especially of simple, feather-veined leaves and some compound, pinnate forms; or the expansion of the blade is primary and the formation of the chief veins secondary, as in many three-parted, pinnate, and palmate leaves. 
No. 487]

THE DEVELOPMENT OF LEAVES

437

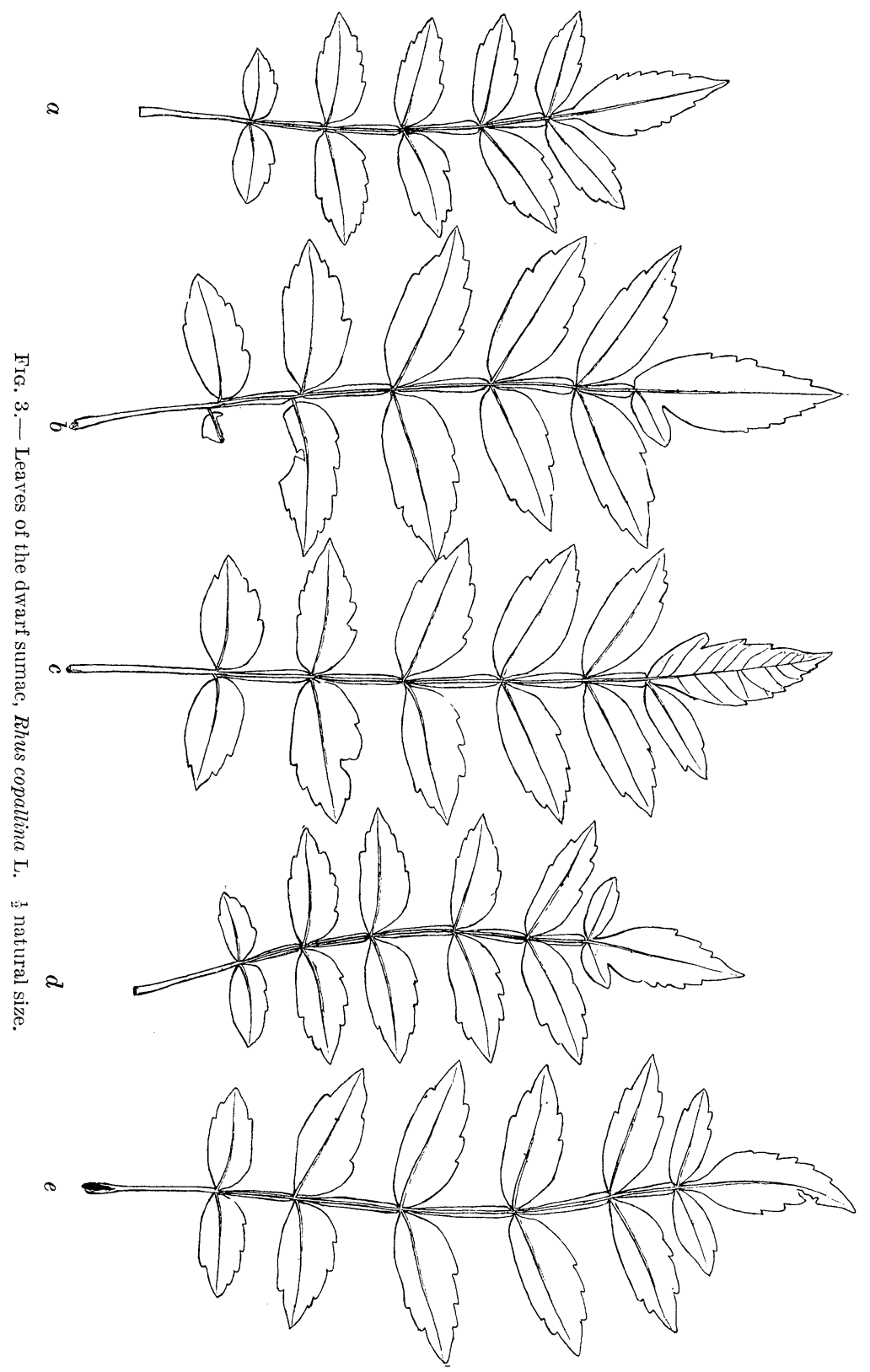

This content downloaded from 192.148.225.018 on July 16, 2017 21:20:14 PM All use subject to University of Chicago Press Terms and Conditions (http://www.journals.uchicago.edu/t-an 
The development of a leaf to this point is characterized by segmentation of its parts, accompanied by relatively little increase in volume. This is its embryonic stage. It is followed by the stage of expansion in which there is a great increase in volume without the addition of lobes or leaflets. The recognition of these two fundamental stages in leaf development is essential in interpreting mature leaves.

The embryonic development of the rose leaf is shown in Figure $4 a, b$, and $c . A$ is from Sir John Lubbock's drawing of the growing point, with side views of two primordial leaves in successive stages of development. He states ${ }^{1}$ that the leaf "commences as a small knob at the side of, and immediately below the growingpoint. When this knob has reached a certain length it presents two lobes (as on the left of the drawing).... The lower lobe is one of the stipules, which according to Schacht appear first .... The stipule appears almost simultaneously with the first and upper leaflet, before any of the lower and later ones. These originate close above the stipules." On the right of Figure $4 a$, the leaf presents lower lobes for the stipules, middle lobes for a pair of leaflets, and an upper. lobe for the terminal leaflet. If by an arrest of development the stage of expansion should begin at this time, we should expect such a mature leaf as in Fig. $4 d$. Expansion at the younger stage shown in $a$ would produce a leaf like $e$; and at a still earlier stage, when the primordial leaf was but slightly indented, the stipules and blade would be scarcely separable, as in $f$.

Later stages in the embryonic development of the rose leaf are presented in $b$ and $c$, after Trécul. They show the addition of the second and third pairs of leaflets respectively. It may be noted that in Eichler's opinion Trécul was misled by the early large size of the stipules into believing that they formed before the leaflets. Eichler finds that in various types of leaves the stipules may arise either as the first or the last of the primary divisions of the leaf blade, or at some intermediate time. In the rose they form last (loc. cit. pp. 26-27). If this were true, however, one might expect to find certain mature leaves without stipules, but such do not occur. The fact that if a mature leaf shows only

\footnotetext{
${ }^{1}$ Lubbock, J. On Buds and Stipules. London, 1899, 233 pp.
} 
two divisions they will be terminal leaflet and stipules is in harmony with the early origin of the stipules as stated by Trécul and Lubbock.

The embryology of a basifugal leaf is shown in Fig. $4 \mathrm{~g}$. Since drawings of the sumac are not available, Trécul's figure of Gleditschia ferox has been substituted. The youngest leaf, $l^{\prime}$, is without lobes; in the older leaf, $l^{\prime \prime}$, the stipules $(s)$ have appeared; and in the oldest leaf a succession of leaflets is forming from the base

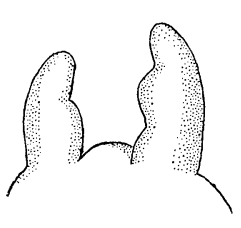

$a$

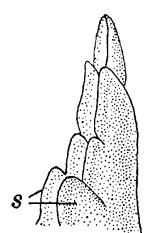

$b$

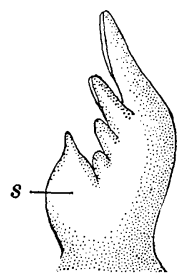

$c$

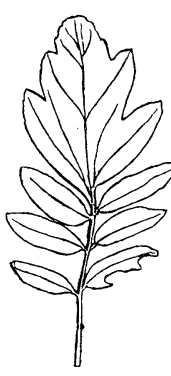

$h$

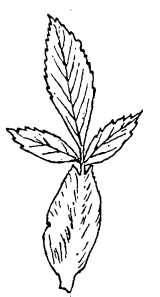

$d$
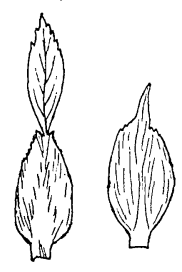

$f$

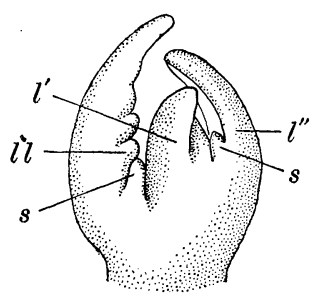

$g$
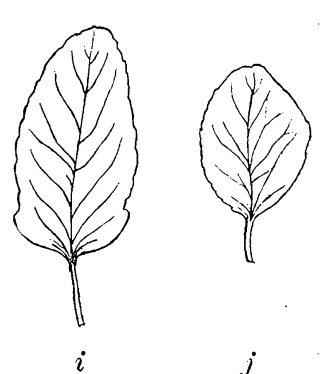

FIG. 4.- Embryonic leaves, and mature leares showing an arrest of embryonic development. $a, b$, and $c$, embryonic rose leaves, $a$ after Lubbock, $b$ and $c$ after Trécul. $d, e$, and $f$, mature rose leaves. $g$, embryonic leaves of Glcditschia ferox, after Trécul. $h, i$, and $j$, mature leaves of Gleditschia triacanthos. The embryonic leaves are considerably magnified; the mature leaves are reduced.

toward the apex (the lowest leaflet is marked $l l$ ). An arrest of development at this stage may produce such a leaf as $h$. The forms $i$ and $j$ may be compared with $l^{\prime \prime}$. In mature leaves of Gleditschia triacanthos the stipules, if retained, are very small and they do not appear in those figured.

From the consideration of the embryology of rose and honey locust leaves it appears that the developmental history may be 
approximately inferred from the variations in mature leaves. The study of the mature leaves is therefore significant, but it ought to be confirmed by embryological examinations.

Evolutionary Significance.-A knowledge of leaf development is of great importance to the paleontologist, and in a paper entitled "Localized Stages in Development in Plants and Animals" Jackson presents a study of mature leaves from a geological and evolutionary point of view. ${ }^{1}$ His conclusions are stated to be in the direct line and the natural outcome of Hyatt's principles of development. Professor Jackson's work upon leaves was continued by Cushman who published three papers on localized stages in this journal. ${ }^{2} \quad$ The leaves at either end of a branch which terminates in a flower are well known to be simpler than those along its middle portion. Simple leaves are expected near the bud scales, the sepals, and the cotyledons. St. Hilaire (quoted by Trécul) sought to explain this arrangement by nutritive conditions; the simple leaves in the young plant or near the flower are due to weakness and exhaustion. In full vigor leaves tend to become compound, and there are some instances in which cultivation in rich soil has favored the production of compound leaves. This explanation is not satisfactory, however, and Jackson proposes another. The early leaves are said to represent the adult types of ancestral forms; and the successive leaves between the cotyledons and the most complex forms which the plant produces record the evolutionary history of the species. The simplification of leaves toward the flower is considered a senile repetition, in reverse order, of the developmental series. In localized parts of the adult, as at the base of vigorous shoots, stages of leaf development may be found similar to those of young plants; their equivalents are to be sought in the adults of ancestral groups.

The nature of ancestral forms is for the geologist to decide; it

${ }^{1}$ Jackson, R. T. Localized Stages in Development in Plants and Animals. Mem. of the Boston Soc. of Nat. Hist., 1899, vol. 5, no. 4, pp. 89-153.

${ }^{2}$ Cushman, J. A. Studies of Localized Stages of Growth in Some Common New England Plants. Amer. Nat., 1902, vol. 36, pp. 865-885.

Studies of Localized Stages in Some Plants of the Botanic Gardens of Harvard University. Amer. Nat., 1903, vol. 37, pp. 243-259.

Localized Stages in Common Roadside Plants. Amer. Nat., 1904, vol. 38, pp. $819-832$. 
is generally assumed that their leaves were simpler in outline than those of existing species. If, however, it is true that the plant is recording its history in producing these simpler leaves, the reason why they occur in the places named remains as much a mystery as ever. 'The plant just before producing' a flower can scarcely be regarded as weak, exhausted, or senile. The embryologist is content to find that the diverse forms of mature leaves arise from papillae which become characteristically lobed and molded before they expand. If expansion occurs before the modelling is complete, a simple form of leaf results. A more accurate account of the development of the papillae in various plants ought, however, to be obtained.

\section{SUMMary.}

Certain features of leaf development which were established some fifty years ago, should not be overlooked. These are primarily the basipetal and basifugal types of growth, which may be verified by collecting mature leaves, and which can profitably be taught to students of elementary botany.

Among the basipetal leaves of the earlier writers there are two radically different types, represented by the rose and blackberry respectively. The rose should be separated from this class and its leaf development may be described as stipular. Mature leaves indicate that the rose stipules are formed before the lateral leaflets, as observed by Trécul and Lubbock but denied by Eichler.

The formation of relatively simple leaves in plants which bear lobed or compound forms may be described embryologically, as an arrest of development in the primordial leaf followed by a stage of expansion, or by expansion before the embryological stage has been completed. Rapidity of growth may account for the constant location of the simpler leaves near the cotyledons, bud scales and sepals.

Cambridge, Mass. 